\title{
Survival of group A streptococci in dried human blood
}

\author{
J. C. REITMEYER, A. EWERT, M. A. CRAWFORD*, GERALYN R. REITMEYER $\dagger$ and LUCIA MOCK $\dagger$
}

Department of Microbiology, "Integrated Functional Laboratory and $\dagger$ Blood Bank, University of Texas Medical Branch, Galveston, Texas 77555, USA

\begin{abstract}
Summary. The resurgence of streptococcal infections in the USA and Europe and their high incidence in other parts of the world prompted an examination of the survival and maintenance of virulence of group A streptococci. Human blood containing group A streptococci was placed on small pieces of sterile paper towelling and allowed to dry at room temperature. At periods of 2, 8, 15 and 20 weeks later, the paper with the dried blood was placed in Todd-Hewitt broth and incubated at $37^{\circ} \mathrm{C}$ overnight. All the samples tested at 2 weeks grew in broth, and with only one exception, grew in fresh human blood provided by five donors. At 8 weeks only two of the 10 strains failed to grow in broth; seven of the eight viable cultures also grew in blood. At 15 and 20 weeks after drying the eight cultures were still viable. Since seven were able to grow in fresh blood as well as in broth it is assumed that their virulence factor(s) had been retained.
\end{abstract}

\section{Introduction}

Group A streptococci are major human pathogens. Acute rheumatic fever (ARF) is still an important medical problem in some countries, such as India, where it has been estimated that over six million children of school age are afflicted with rheumatic heart disease. ${ }^{1}$ The incidence of this disease in the USA and Europe has declined dramatically over the years, but recently ARF was reported in Ohio, Pennsylvania, and Utah, ${ }^{2-6}$ and for the first time in over two decades at the US Naval Training Center at San Diego, California. ${ }^{7}$ An outbreak of ARF also occurred in army trainees at Fort Leonard Wood in Missouri, ${ }^{8}$ and a Centers for Disease Control survey during the mid-1980s showed that six of the 24 states with passive surveillance for ARF reported a two-fold increase in cases. ${ }^{2}$ The rates of ARF among all other races are several times higher than those among whites, ${ }^{2}$ and one study reported rates of ARF in an inner-city to be more than five times higher than in suburbia. ${ }^{9}$ Reasons for the resurgence of ARF are not clear. There have also been case reports of severe toxic shock-like syndrome, ${ }^{10,11}$ septicaemia in adults ${ }^{12,13}$ and children ${ }^{14}$ and sudden death ${ }^{15}$ due to streptococcal infections.

Transmission of streptococcal infections has been attributed to close personal contact. Rammelkamp et al. ${ }^{16}$ reported that cultures of streptococci isolated from dust in military barracks, although viable, had lost their virulence as they did not induce infection when tested in human volunteers.

One of the factors associated with virulence in streptococci is type-specific M-protein that inhibits

Received 4 May 1992; revised version accepted 4 June 1992. phagocytosis, ${ }^{17-22}$ and the ability to produce Mprotein can be reduced or lost by repeated subculture in artificial media. ${ }^{17,18,23}$ Survival and virulence of group A streptococci can also be lost by inappropriate use of holding methods or transport medium and storage at $4{ }^{\circ} \mathrm{C} .{ }^{23}$ Furthermore, the hyaluronic acid capsule has been implicated as a virulence factor in group A streptococci. ${ }^{24}$

Viability, as well as virulence, of streptococci and other organisms can normally be preserved for many years by special freezing at or below $-70^{\circ} \mathrm{C}$ or by lyophilisation. ${ }^{23}$ The use of a plastic strip contaminated by human saliva has been reported to maintain viability of oral micro-organisms including $S$. mutans for up to 8 weeks at room temperature. ${ }^{25}$

\section{Materials and methods}

\section{Cultures}

Nine of the 10 strains of group A streptococci were obtained from Dr Ellen Whitnack of the University of Tennessee at Memphis. The strains were designated either by a person's name or by letters and numbers identifying their origin. Eight of the strains were isolated from patients with ARF (M, M-type 5; and V, M-type 24), or acute glomerulonephritis (AGN) of throat origin (NTA-266, M-type 12; NTA-2, M-type 2), or AGN from skin lesions (NSA-69, M-type 56; NAS-100, M-type 43; NAS-75 and NSA-156, both Mtype 49). Strain S-43, from the Lancefield collection, was designated as the type strain for M-type 6 (American Type Culture Collection, ATCC 12349). The tenth culture, M-type 12, was ATCC 12351. The 
strains were removed from liquid nitrogen storage and grown three times consecutively in fresh human blood before use.

\section{Drving procedure}

Ten $\mu$ of blood from each of the 10 cultures were placed on $15-\mathrm{mm}$ square pieces of sterile paper towelling (Fort Howard Corp.. Green Bay, WI, USA) commonly used in medical establishments. The blood on the paper was allowed to dry at ambient temperature $\left(23^{\circ} \mathrm{C}\right)$ in sterile plastic petri dishes. For three of the strains. $100-\mu 1$ volumes of the cultures in blood were placed in sterile plastic tubes $(13 \times 75 \mathrm{~mm})$ and allowed to dry at $23^{\circ} \mathrm{C}$.

\section{Source's of blood}

All tive donors were $>50$ years old, in good health and without young children in their household. None had experienced diagnosed streptococcal infections in the past 5 years nor had a history of post-streptococcal sequelae. Two worked with streptococci, including the strains used in this study as well as with non-A groups. Two were blood bank nurses who worked predominantly with healthy adult donors. The fifth had little contact with patients or cultures of streptococci.

\section{Growth of organisms}

A paper with dried blood was placed in a sterile plastic tube $(12 \times 75 \mathrm{~mm}): 1 \mathrm{ml}$ of Todd-Hewitt Broth (THB) with Neopeptone $0.5 \%$ and Dextrose $0.5 \%$ (Difco Laboratories, Detroit MI. USA) was then added.

\section{Testing for rirulence}

Determination of virulence was based on detection of the anti-phagocytic activity of $\mathrm{M}$-protein of the various streptococci by the bacterial test described by Maxted. ${ }^{26}$ In this test $5 \mu$ lof an overnight culture were added to a $12 \times 75 \mathrm{~mm}$ plastic tube or $1.5-\mathrm{ml}$ microcentrifuge tube containing $400 \mu \mathrm{l}$ of fresh heparinised blood from each of the five donors. After mixing, $1 \mu 1$ was streaked on to a blood-agar plate. The tubes were incubated at $37^{\circ} \mathrm{C}$ for $3 \mathrm{~h}$. with rotation at $5 \mathrm{rpm}$. After incubation. $1 \mu \mathrm{l}$ was streaked on to a blood-agar plate to determine whether organisms survived, multiplied or were phagocytosed. The ability of each strain to survive or multiply in the blood of each donor had been established by incubating the specimen in fresh blood before being allowed to dry at room temperature.

\section{Results}

After being held for 2 weeks at ambient temperature all 10 strains were able to grow in THB. When inoculated into each donor blood, nine strains responded as before. The ATCC (M-type 12) strain appeared to lose its $\mathrm{M}$-protein because it was phagocytosed by leukocytes in blood from all the donors.

The strains were re-tested 6 weeks later, 8 weeks after the initial drying. Eight of the strains grew in THB and when inoculated into the five donors' blood, seven responded as before. One strain (NTA-2) which had grown in the blood of two donors failed to grow at this time. The ATCC (M-type 12) strain and the S-43 (M-type 6) strain from the Lancefield collection failed to grow in broth and thus could not be tested in blood. An opportunity to observe an additional control occurred when one strain (NSA-156) became contaminated with Staphylococcus epidermidis which appeared in all the "before" cultures. After incubation in blood for $3 \mathrm{~h}$, the "after" plates were either devoid of all organisms or contained only the streptococci that they had grown previously, indicating that all of the blood samples were capable of phagocytosis.

When all 10 strains were re-tested 15 weeks after the initial drying, the results were identical to those obtained when tested after 8 weeks.

All strains except NTA-2 that grew in broth also grew in blood 20 weeks after the initial drying and those that grew in blood formed mucoid colonies, indicating that their ability to produce a hyaluronic capsule as well the $\mathrm{M}$-protein had been retained.

Table. Growth patterns of group A streptococci in fresh human blood before and after drying

\begin{tabular}{|c|c|c|c|c|c|c|c|c|c|c|}
\hline \multirow{3}{*}{ Strain no. } & \multicolumn{10}{|c|}{ Donors } \\
\hline & \multicolumn{2}{|c|}{ JCR } & \multicolumn{2}{|c|}{$\mathrm{AE}$} & \multicolumn{2}{|c|}{$\mathrm{MAC}$} & \multicolumn{2}{|c|}{ GRR } & \multicolumn{2}{|c|}{ L.M } \\
\hline & $\mathrm{b}$ & & $\mathrm{b}$ & $a$ & $\mathrm{~b}$ & $\mathrm{a}$ & $b$ & $\mathrm{a}$ & $\mathrm{b}$ & $\mathrm{a}$ \\
\hline $\begin{array}{l}\text { NTA-2* } \\
(\mathrm{M}-2)\end{array}$ & $\mathbf{M}$ & $P$ & $\mathbf{M}$ & $\mathrm{P}$ & $\mathbf{P}$ & $\mathrm{P}$ & $\mathrm{S}$ & $\mathbf{P}$ & $\mathbf{P}$ & $\mathrm{P}$ \\
\hline $\begin{array}{l}M \\
(M-5)\end{array}$ & $\mathbf{M}$ & M & $\mathbf{M}$ & $\mathrm{M}$ & $\mathrm{S}$ & $\mathbf{M}$ & $\mathbf{M}$ & $\mathbf{M}$ & $\mathbf{M}$ & M \\
\hline $\begin{array}{l}S-43+ \\
(M-6)\end{array}$ & $P$ & $\mathrm{P}$ & $\mathrm{M}$ & $\mathrm{M}$ & $\mathrm{P}$ & $P$ & $\mathrm{M}$ & $\mathrm{M}$ & $\mathrm{M}$ & M \\
\hline $\begin{array}{l}\text { ATCC } 12351 \\
(\mathrm{M}-12)\end{array}$ & $\mathrm{M}$ & $\mathbf{P}$ & $\mathbf{M}$ & $\mathrm{P}$ & $\mathbf{M}$ & $\mathrm{P}$ & $\mathbf{P}$ & $\mathrm{P}$ & $\mathrm{M}$ & $\mathrm{P}$ \\
\hline $\begin{array}{l}\text { NTA-266 } \\
(\mathrm{M}-12)\end{array}$ & $\mathrm{M}$ & $\mathbf{M}$ & $\mathrm{P}$ & $P$ & $P$ & $\mathbf{P}$ & $P$ & $\mathbf{P}$ & $\mathbf{M}$ & $\mathbf{M}$ \\
\hline $\begin{array}{l}V \\
(M-24)\end{array}$ & $M$ & $\mathbf{M}$ & $\mathbf{P}$ & $\mathbf{P}$ & $\mathrm{M}$ & $\mathrm{S}$ & $\mathbf{M}$ & $\mathrm{S}$ & $\mathrm{M}$ & $\mathbf{M}$ \\
\hline $\begin{array}{l}\text { NSA-100 } \\
(\mathrm{M}-43)\end{array}$ & $M$ & $\mathrm{M}$ & $\mathbf{M}$ & $\mathrm{M}$ & $\mathrm{M}$ & M & $\mathrm{M}$ & $\mathbf{M}$ & $\mathrm{M}$ & $\mathbf{M}$ \\
\hline $\begin{array}{l}\text { NSA-75 } \\
(\mathrm{M}-49)\end{array}$ & $M$ & $\mathbf{M}$ & $\mathbf{M}$ & $\mathbf{M}$ & $\mathbf{M}$ & M & $\mathrm{M}$ & $\mathbf{M}$ & $\mathrm{M}$ & $\mathrm{M}$ \\
\hline $\begin{array}{l}\text { NAS-156 } \\
(\mathrm{M}-49)\end{array}$ & $\mathrm{M}$ & $\mathrm{M}$ & $\mathrm{S}$ & S & S & M & $\mathrm{S}$ & S & $\mathrm{M}$ & $\mathbf{M}$ \\
\hline $\begin{array}{l}\text { NTA-69 } \\
(\mathrm{M}-56)\end{array}$ & $\mathrm{M}$ & $\mathbf{M}$ & $\mathrm{S}$ & $S$ & M & M & M & $\mathbf{M}$ & M & $\mathrm{M}$ \\
\hline \multicolumn{11}{|c|}{$\begin{array}{l}\text { b. before drying; a, after drying: } S \text {, survived (numbers approxi- } \\
\text { mately the same before and after incubation in blood); } M \text {, multiplied } \\
\text { (numbers at least doubled after incubation in blood); } P \text {, phago- } \\
\text { cytosed (at least } 50 \% \text { fewer than before incubation in blood). } \\
* \text { Did not grow in blood after second week. } \\
+ \text { Did not grow in broth after second week. }\end{array}$} \\
\hline
\end{tabular}


The tubes containing dried blood were tested for growth after 1 and 6 months in THB only. All three strains grew in the broth.

The growth patterns for the 10 strains in blood from all five donors are presented in the table.

\section{Discussion}

Results indicate that the virulence factors are maintained in dried blood. The ability of streptococci to survive in the dried state for several months is not as surprising as was the observation that their M-protein, which can be lost quite easily, was preserved.

\section{References}

1. Agarwal BL. Rheumatic heart disease unabated in developing countries. Lancet 1981; 1: 910-911.

2. Asay E, Giles R, Veasy LG, Hill HR, Ware J, Nicholes HR. Acute rheumatic fever-Utah. $M M W R$ 1987; 36: 108-110, 115.

3. Congeni B, Rizzo C, Congeni J, Sreenivasan VV. Outbreak of acute rheumatic fever in northeast Ohio. J Pediatr 1987; 111: $176-179$

4. Hosier DM, Craenan JM, Teske DW, Wheller JJ. Resurgence of acute rheumatic fever. Am J Dis Child 1987; 141: $730-733$.

5. Veasy LG, Weidmeier SE, Orsmond GS et al. Resurgence of acute rheumatic fever in the intermountain area of the United States. $N$ Engl J Med 1987; 316: 421-427.

6. Wald ER, Dashefsky B, Feidt C, Chiponis D, Byers C. Acute rheumatic fever in western Pennsylvania and the tristate area. Pediatrics $1987 ; 80: 371-374$.

7. Papadimos T, Escamilla J, Garst P, Centers for Disease Control. Acute rheumatic fever at a Navy Training Center-San Diego, California. $M M W R$ 1988; 37: 101-104.

8. Sampson GL, Williams RG, House MD, Centers for Disease Control. Acute Rheumatic fever among Army traineesFort Leonard Wood, Missouri, 1977-1988. MMWR 1988; 37: 519-522.

9. Land MA, Bisno AL. Acute Rheumatic fever: a vanishing disease in suburbia. JAMA 1983; 249: 895-898.

10. Cone LA, Woodard DR, Schlievert PM, Tomory GS. Clinical and bacteriologic observations of a toxic shock-like syndrome due to Streptococcus pyogenes. N Engl J Med 1987; 317: 146-149.

11. Bartter T, Dascal A, Carroll K, Curley FJ. Toxic strep syndrome: a manifestation of group A streptococcal infection. Arch Intern Med 1988; 148: 1421-1424.

12. Stevens DL, Tanner MH, Winship J et al. Severe group A streptococcal infections associated with a toxic shock-like syndrome and scarlet fever toxin A. N Engl J Med 1989; $321: 1-7$.

13. Voeck C, Armstrong N, Trail F et al. Centers for Disease
Eight of the 10 strains dried on paper towelling were able to survive and seven were able to grow in human blood after 20 weeks. The three strains in plastic tubes grew in broth after having been held in the dried state for more than 6 months. Since the ability to grow in fresh blood is taken as proof of virulence, seven of the strains appeared to be potentially pathogenic.

It is important to recognise that pathogenic organisms can survive in the environment for some time, and in view of this it is important to re-assess protocols in laboratories concerning items that may be contaminated with blood that contains micro-organisms, particularly in regard to methods of safe disposal.

Control. Group A beta-hemolytic streptococcal bacteremia-Colorado, 1988. MMWR 1990; 39: 3-6.

14. Wheeler MC, Roe MH, Kapan EL, Schlievert PM, Todd JK. Outbreak of group A streptococcus septicemia in children. Clinical, epidemiologic, and microbiologic correlates. JAMA 1991; 266: 533-537.

15. Hartsough AB, Henry TE, Parks BO. Sudden death due to streptococcal infection. J Forensic Sci 1991 ; 36: 1485-1491.

16. Rammelkamp CH, Denny FW, Wannamaker LW. In: Thomas L (ed) Rheumatic fever (Studies on the epidemiology of rheumatic fever in the armed services). Minneapolis, University of Minnesota Press. 1952: 72-89.

17. Todd EW, Lancefield RC. Variants of hemolytic streptococci; their relationship to type-specific substance, virulence, and toxins. J Exp Med 1928; 48: 751-767.

18. Lancefield RC. Current knowledge of type-specific $M$ antigens of group A streptococci. J Immunol 1962; 89: 307-313.

19. van de Rijn I, Fischetti VA. Immunochemical analysis of intact $\mathrm{M}$ protein secreted from cell wall-less streptococci. Infect Immun $1981 ; 32: 86-91$.

20. Manjula BN. Molecular aspects of the phagocytosis resistance of group A streptococci. Eur J Epidemiol 1988; 4: 289-300.

21. Fischetti VA. Streptococcal $M$ protein: molecular design and biological behaviour. Clin Microbiol Rev 1989; 2: 285-314.

22. Wilson AT. The relative importance of the capsule and the Mantigen in determining colony form of group A streptococci. J Exp Med 1959; 109: 257-270.

23. Facklam RR, Carey RB. Streptococci and aerococci. In: Lennetti EH (ed) Manual of clinical microbiology, 4th edn. Washington, D.C. American Society for Microbiology 1985: 156-157.

24. Wessels MR, Moses AE, Goldberg JB, DiCesare TJ. Hyaluronic acid capsule is a virulence factor for mucoid group A streptococci. Proc Natl Acad Sci USA 1991; 88: 8317-8321.

25. del Rio Gomez I, Bratthall D. Sample, count, identify and store the mutans streptococci. Scand J Dent Res 1990; 98: 106-111.

26. Maxted WR. The indirect bactericidal test as a means of identifying antibody to the $\mathrm{M}$ antigen of Streptococcus pyogenes. Br J Exp Pathol 1956; 37: 415-422. 